\title{
Relationships of Handgrip Strength with Menstruation-Related Symptoms in Female University Students in Japan
}

\author{
Yukie Matsuura ${ }^{1}$, Honoka Atsumi ${ }^{2}$, Erina Kane ${ }^{3}$, Mizuki Yano², Kiko Akamine², \\ Ayumi Murakami ${ }^{2}$, Tokimi Wada ${ }^{4}$, Toshiyuki Yasui ${ }^{1}$ \\ ${ }^{1}$ Department of Reproductive and Menopausal Medicine, Graduate School of Biomedical Sciences, Tokushima University, \\ Tokushima, Japan \\ ${ }^{2}$ Graduate School of Health Sciences, Tokushima University, Tokushima, Japan \\ ${ }^{3}$ Nursing Department, Tokushima University Hospital, Tokushima, Japan \\ ${ }^{4}$ Nursing Department, Osaka Medical College Hospital, Osaka, Japan \\ Email: *y.matsuura@tokushima-u.ac.jp
}

How to cite this paper: Matsuura, Y., Atsumi, H., Kane, E., Yano, M., Akamine, K., Murakami, A., Wada, T. and Yasui, T. (2020) Relationships of Handgrip Strength with Menstruation-Related Symptoms in Female University Students in Japan. Open Journal of Obstetrics and Gynecology, 10, 1056-1066

https://doi.org/10.4236/ojog.2020.1080099

Received: July 24, 2020

Accepted: August 17, 2020

Published: August 20, 2020

Copyright $\odot 2020$ by author(s) and Scientific Research Publishing Inc. This work is licensed under the Creative Commons Attribution International License (CC BY 4.0)

http://creativecommons.org/licenses/by/4.0/

\begin{abstract}
Introduction: Some somatic and psychological disorders have been associated with handgrip strength, which is an easy, inexpensive and noninvasive method for assessment of muscle strength. We conducted a cross-sectional study to clarify the relationship of handgrip strength and menstruation-related symptoms. Material and Methods: Handgrip strength was measured and a self-administered questionnaire was performed in female university students in Japan. Results: Handgrip strength did not significantly differ among the menstrual phases. The mean handgrip strength level $(n=260)$ was $26.0 \pm 3.9$ $\mathrm{kg}$. We divided the subjects into three groups according to the handgrip strength level. Handgrip strength was associated with degrees of depression and anxiety during menstruation. Conclusion: This can be used as fundamental data in further clarifying the relationship between muscle strength and menstruation-related symptoms.
\end{abstract}

\section{Keywords}

Handgrip Strength, Menstruation-Related Symptoms, Menstrual Phases, Young Women

\section{Introduction}

Menstruation-related symptoms, including physical and psychological symptoms, have recently become a social issue. The proportion of women suffering 
from menstruation-related symptoms such as premenstrual symptoms and symptoms during menstruation has been increasing in Japan for not only working women [1] but also students in high school [2] and university [3] [4].

Measurement of handgrip strength is an easy, inexpensive and noninvasive method for assessment of muscle strength, and it has been used for assessment of muscle strength in the Japanese population [5] and for sarcopenia diagnosis criteria [6]. Associations of handgrip strength level with various diseases such as cardiovascular diseases, respiratory diseases and cancer and quality of life have been reported in a young age group as well as an elderly age group in different areas [6]-[11]. In addition, it has been reported that lower handgrip strength was associated with psychological symptoms such as depression and anxiety [12] [13] [14].

Based on the evidence that handgrip strength is associated with psychological symptoms as well as physical symptoms and several diseases in all age groups, we hypothesized that menstruation-related symptoms in young women may be related to handgrip strength. We conducted this study to clarify the relationship between handgrip strength and menstruation-related symptoms during menstruation in female university students in Japan.

\section{Materials and Methods}

This was a cross-sectional study targeting female university students in Japan. We first conducted a preliminary study in July 2019 to clarify whether there is a difference in handgrip strength depending on the phase of the menstrual cycle including menstrual phase, follicular phase and luteal phase. We recruited 20 female nursing students and measured their handgrip strengths in the menstrual phase, follicular phase and luteal phase over a period of one month.

After the preliminary study, the main study was conducted from July to August in 2019. We recruited 278 female university students. The students were asked to complete a questionnaire at the end of a lecture, then measured their handgrip strength with guidance from researchers. The questionnaires were collected on the same day. Informed consent was obtained prior to participation in the study including the preliminary study. This study including the preliminary study was approved by the Ethics Committee of Tokushima University Hospital (approval number: 3483 ).

In this study, we defined menstruation-related symptoms as uncomfortable symptoms that women recognize during menstruation, including psychical symptoms such as abdominal pain, headache, constipation, diarrhea, abdominal distension, getting tired easily, edema, sleepiness, backache, nausea, rough skin, thirst and psychological symptoms such as increase in appetite, irritation, depression, loss of motivation and anxiety.

\subsection{Questionnaire}

We designed a self-administered questionnaire that took about 10 minutes to 
complete. The first part of the questionnaire consisted of questions on age, body height and weight, menstrual cycle and present phase of the menstrual cycle. Phases of the menstrual cycle include the menstrual phase (during menstruation), follicular phase (2 to 4 days after the start of last menstruation) and luteal phase (21 to 25 days after the start of the last menstruation). The second part of the questionnaire consisted of questions on self-assessment of menstruation-related symptoms during menstruation. The items were rated on a scale from 0 to 4 points ( 0 points: no symptom, 1 point: unrecognizable, 2 points: bearable, 3 points: unrecognizable if taking medication, 4 points: affecting daily life).

\subsection{Instrument for Measuring Handgrip Strength}

Handgrip strength was measured by using a handgrip strength dynamometer (GRIP-D, Takei Scientific Instruments Co., Ltd., Japan, Product No. T.K.K.5401). We asked the subjects to hold the device so that the handgrip meter indicator faces outward and to turn the knob to adjust the handgrip width so that the second joint of the pointing finger makes a right angle. Each subject stood upright with arms down naturally and clasped the handgrip with full force. Measurements were performed twice each with the left and right hands alternately. The mean value of the highest values of the forces of both hands was indicated on the display of the handgrip strength dynamometer.

\subsection{Statistical Analysis}

Baseline characteristics of the participants including age, height, weight, BMI and handgrip strength are presented as means and standard deviation (SD). Each categorized variable is expressed as number with percentage. One-way analysis of variance (ANOVA) was used to determine statistically significant differences in handgrip strength in the three menstrual phases. We divided the students into three groups by handgrip strength level. Comparisons of age, height, weight and BMI among the three groups were performed by using one-way ANOVA. Comparisons of menstrual cycle, present phases of the menstrual cycle and intensity of each menstruation-related symptom among the three groups were performed by the chi-square test. Statistical analyses were carried out by using SPSS version 24 for Windows. All $\mathrm{p}$ values less than 0.05 were considered to be statistically significant.

\section{Results}

\subsection{Differences in Handgrip Strength According to Menstrual Phase}

As a preliminary study, handgrip strength was measured by 19 students three times, and data for 8 students who could measure handgrip strengths in all three menstrual phases were used for analysis. The mean age of the participants was $21.4 \pm 0.7$ years, mean height was $160.1 \pm 4.2 \mathrm{~cm}$, mean weight was $54.0 \pm 5.7 \mathrm{~kg}$ and mean BMI was $21.0 \pm 1.9 \mathrm{~kg} / \mathrm{m}^{2}$. Mean handgrip strengths did not differ 
between the three phases (menstrual vs follicular vs luteal phase: $26.5 \pm 4.7,27.1$ \pm 5.0 , and $26.5 \pm 4.6 \mathrm{~kg}$, respectively).

\subsection{Background Characteristics of the Subjects}

The questionnaire was distributed to 278 students, and we received responses from 269 students (96.8\%). We analyzed data for 260 students (93.5\%) excluding 8 students who did not measure handgrip strength and one student who did not give any answer for symptoms. The mean age of the participants was $20.0 \pm 2.7$ years, mean height was $158.0 \pm 4.8 \mathrm{~cm}$, mean weight was $51.0 \pm 6.1 \mathrm{~kg}$ and mean BMI was $20.4 \pm 2.1 \mathrm{~kg} / \mathrm{m}^{2}$. Durations of the menstrual cycle were less than 24 days in $5.4 \%$ of the students, 25 - 31 days in $63.8 \%$ of the students, 32 - 38 days in $23.8 \%$ of the students, more than 39 days in $5.8 \%$ of the students and unknown in $1.2 \%$ of the students. Handgrip strength levels varied between $17.0 \mathrm{~kg}$ and $36.4 \mathrm{~kg}$, and the mean handgrip strength level was $26.0 \pm 3.9 \mathrm{~kg}$.

\subsection{Menstruation-Related Symptoms}

As can be seen in Table 1, showing the numbers of students who gave answers other than "no symptoms", the most frequent menstruation-related symptom was abdominal pain (88.5\%) followed by sleepiness (82.3\%), irritation (79.2\%), and getting tired easily $(78.1 \%)$.

Table 1. Proportions of subjects who have menstruation-related symptoms.

\begin{tabular}{ccc}
\hline & Number & $(\%)$ \\
\hline Abdominal pain & 230 & $(88.5)$ \\
Sleepiness & 214 & $(82.3)$ \\
Irritation & 206 & $(79.2)$ \\
Getting tired easily & 203 & $(78.1)$ \\
Loss of motivation & 190 & $(73.1)$ \\
Increase in appetite & 185 & $(71.2)$ \\
Backache & 182 & $(70.0)$ \\
Depression & 182 & $(70.0)$ \\
Rough skin & 178 & $(68.5)$ \\
Abdominal distension & 162 & $(62.3)$ \\
Edema & 149 & $(57.3)$ \\
Anxiety & 127 & $(48.8)$ \\
Headache & 124 & $(47.7)$ \\
Constipation & 118 & $(45.4)$ \\
Diarrhea & 118 & $(45.4)$ \\
Nausea & 45 & $(17.3)$ \\
Thirst & $45.3)$ \\
\hline
\end{tabular}




\subsection{Associations of Handgrip Strength with Background and Menstruation-Related Symptoms}

Since handgrip strengths had a wide range $(17.0$ - $36.4 \mathrm{~kg})$, we divided the subjects into three groups according to the handgrip strength level: a low group (handgrip strength $<24.0 \mathrm{~kg}$ ), middle group $(\geq 24.0 \mathrm{~kg}$ and $<28.0 \mathrm{~kg}$ ) and high group ( $\geq 28.0 \mathrm{~kg}$ ). The proportions of students were $30.8 \%$ in the low group, $40.4 \%$ in the middle group and $28.8 \%$ in the high group (Table 2). Handgrip strength had significant associations with body height $(\mathrm{p}=0.022)$, body weight $(\mathrm{p}<0.001)$ and BMI $(\mathrm{p}=0.001)$. However, handgrip strength was not significantly associated with age, duration of the menstrual cycle or present phase of the menstrual cycle. As can be seen in Table 3, there was no significant association between handgrip strength level and degrees of physical symptoms in menstruation-related symptoms, except for getting tired easily, which tended to have an association $(p=0.074)$. With regard to degrees of psychological symptoms in menstruation-related symptoms, handgrip strength level was associated with degree of depression $(\mathrm{p}=0.011)$ and degree of anxiety $(\mathrm{p}=0.037)($ Table 4$)$.

Table 2. Background characteristics according to the tertiles of handgrip strength.

\begin{tabular}{|c|c|c|c|c|c|c|c|c|}
\hline & & \multicolumn{6}{|c|}{ Handgrip strength } & \multirow[b]{2}{*}{$P$-value } \\
\hline & & \multicolumn{2}{|c|}{ Low } & \multicolumn{2}{|c|}{ Middle } & \multicolumn{2}{|c|}{ High } & \\
\hline Number & & \multicolumn{2}{|c|}{80} & \multicolumn{2}{|c|}{105} & \multicolumn{2}{|c|}{75} & \\
\hline Handgrip strength $(\mathrm{kg})^{\star}$ & & 21.8 & $(1.8)$ & 25.9 & $(1.2)$ & 30.8 & $(2.2)$ & $<0.001$ \\
\hline Age $\left(\right.$ years) ${ }^{*}$ & & 19.7 & $(1.6)$ & 20.2 & $(2.6)$ & 20.2 & $(3.7)$ & 0.381 \\
\hline Height $(\mathrm{cm})^{\star}$ & & 157.3 & $(4.4)$ & 157.7 & $(4.8)$ & 159.3 & (5.3) & 0.022 \\
\hline Weight $(\mathrm{kg})^{\star}$ & & 48.7 & $(5.0)$ & 51.2 & (6.5) & 53 & (6.0) & $<0.001$ \\
\hline $\operatorname{BMI}\left(\mathrm{kg} / \mathrm{m}^{2}\right)^{*}$ & & 19.7 & (1.8) & 20.6 & $(2.2)$ & 20.9 & $(2.0)$ & 0.001 \\
\hline Menstrual cycle & $<24$ days & 1 & (1.3) & 8 & (7.7) & 5 & (6.8) & 0.580 \\
\hline \multirow[t]{3}{*}{$(\mathrm{n}=257)$} & 25 - 31 days & 54 & $(68.4)$ & 64 & $(61.5)$ & 48 & $(64.9)$ & \\
\hline & 32 - 38 days & 19 & $(24.1)$ & 27 & $(26.0)$ & 16 & $(21.6)$ & \\
\hline & $>39$ days & 5 & $(6.3)$ & 5 & $(4.8)$ & 5 & $(6.8)$ & \\
\hline \multirow{4}{*}{$\begin{array}{l}\text { Menstrual phase } \\
\qquad(\mathrm{n}=259)\end{array}$} & Luteal & 40 & $(50.0)$ & 43 & $(41.3)$ & 37 & $(49.3)$ & 0.446 \\
\hline & Menstrual & 20 & $(25.0)$ & 22 & $(21.2)$ & 16 & (21.3) & \\
\hline & Follicular & 9 & (11.3) & 24 & (23.1) & 15 & $(20.0)$ & \\
\hline & don't know & 11 & (13.8) & 15 & (14.4) & 7 & (9.3) & \\
\hline
\end{tabular}

Number (\%). ${ }^{*}$ Numbers indicate means (standard deviation) for handgrip strength, age, height, weight and BMI. One-way ANOVA.

Table 3. Associations of handgrip strength levels with degrees of physical symptoms in menstruation-related symptoms.

\begin{tabular}{rcccccccr}
\hline & & \multicolumn{5}{c}{ Handgrip strength } \\
\cline { 3 - 7 } & degree & \multicolumn{2}{c}{ Low (80) } & Middle (105) & High (75) & $P$-value \\
\hline Abdominal pain & 0 & 7 & $(8.8)$ & 10 & $(9.6)$ & 10 & $(13.7)$ & 0.412 \\
\hline
\end{tabular}




\section{Continued}

\begin{tabular}{|c|c|c|c|c|c|c|c|c|}
\hline \multirow[t]{4}{*}{$(\mathrm{n}=257)$} & 1 & 10 & $(12.5)$ & 25 & $(24.0)$ & 14 & $(19.2)$ & \\
\hline & 2 & 21 & $(26.3)$ & 29 & $(27.9)$ & 17 & $(23.3)$ & \\
\hline & 3 & 30 & $(37.5)$ & 27 & $(26.0)$ & 26 & $(35.6)$ & \\
\hline & 4 & 12 & $(15.0)$ & 13 & (12.5) & 6 & $(8.2)$ & \\
\hline Headache & 0 & 43 & (53.8) & 52 & (50.5) & 38 & (51.4) & 0.365 \\
\hline \multirow[t]{4}{*}{$(\mathrm{n}=257)$} & 1 & 12 & $(15.0)$ & 27 & $(26.2)$ & 12 & $(16.2)$ & \\
\hline & 2 & 13 & $(16.3)$ & 14 & $(13.6)$ & 8 & $(10.8)$ & \\
\hline & 3 & 11 & $(13.8)$ & 9 & (8.7) & 15 & $(20.3)$ & \\
\hline & 4 & 1 & (1.3) & 1 & (1.0) & 1 & (1.4) & \\
\hline Backache & 0 & 17 & $(21.3)$ & 36 & $(34.3)$ & 25 & $(33.3)$ & 0.320 \\
\hline \multirow[t]{4}{*}{$(\mathrm{n}=260)$} & 1 & 15 & $(18.8)$ & 11 & $(10.5)$ & 9 & $(12.0)$ & \\
\hline & 2 & 18 & $(22.5)$ & 29 & $(27.6)$ & 15 & $(20.0)$ & \\
\hline & 3 & 21 & $(26.3)$ & 20 & $(19.0)$ & 21 & $(28.0)$ & \\
\hline & 4 & 9 & $(11.3)$ & 9 & (8.6) & 5 & $(6.7)$ & \\
\hline Constipation & 0 & 49 & $(61.3)$ & 55 & $(52.9)$ & 37 & $(49.3)$ & 0.602 \\
\hline \multirow[t]{4}{*}{$(\mathrm{n}=259)$} & 1 & 15 & $(18.8)$ & 22 & $(21.2)$ & 14 & $(18.7)$ & \\
\hline & 2 & 13 & $(16.3)$ & 20 & $(19.2)$ & 18 & $(24.0)$ & \\
\hline & 3 & 2 & $(2.5)$ & 3 & (2.9) & 5 & $(6.7)$ & \\
\hline & 4 & 1 & $(1.3)$ & 4 & $(3.8)$ & 1 & $(1.3)$ & \\
\hline Diarrhea & 0 & 47 & $(59.5)$ & 56 & $(53.3)$ & 38 & $(50.7)$ & 0.462 \\
\hline \multirow[t]{4}{*}{$(\mathrm{n}=259)$} & 1 & 13 & $(16.5)$ & 26 & $(24.8)$ & 14 & $(18.7)$ & \\
\hline & 2 & 12 & $(15.2)$ & 19 & (18.1) & 13 & $(17.3)$ & \\
\hline & 3 & 5 & $(6.3)$ & 3 & $(2.9)$ & 8 & $(10.7)$ & \\
\hline & 4 & 2 & $(2.5)$ & 1 & $(1.0)$ & 2 & $(2.7)$ & \\
\hline Abdominal distension & 0 & 29 & $(36.3)$ & 40 & $(38.1)$ & 28 & $(37.8)$ & 0.427 \\
\hline \multirow[t]{4}{*}{$(\mathrm{n}=259)$} & 1 & 22 & $(27.5)$ & 26 & $(24.8)$ & 17 & $(23.0)$ & \\
\hline & 2 & 22 & $(27.5)$ & 32 & $(30.5)$ & 16 & $(21.6)$ & \\
\hline & 3 & 6 & $(7.5)$ & 4 & $(3.8)$ & 10 & $(13.5)$ & \\
\hline & 4 & 1 & $(1.3)$ & 3 & $(2.9)$ & 3 & $(4.1)$ & \\
\hline Nausea & 0 & 68 & $(85.0)$ & 86 & $(81.9)$ & 60 & $(81.1)$ & 0.568 \\
\hline \multirow[t]{4}{*}{$(\mathrm{n}=259)$} & 1 & 6 & $(7.5)$ & 8 & $(7.6)$ & 5 & $(6.8)$ & \\
\hline & 2 & 5 & $(6.3)$ & 5 & $(4.8)$ & 2 & $(2.7)$ & \\
\hline & 3 & 0 & $(0.0)$ & 4 & (3.8) & 5 & $(6.8)$ & \\
\hline & 4 & 1 & (1.3) & 2 & (1.9) & 2 & $(2.7)$ & \\
\hline & 0 & 35 & $(43.8)$ & 41 & $(39.0)$ & 34 & $(45.9)$ & 0.803 \\
\hline \multirow{4}{*}{$(\mathrm{n}=259)$} & 1 & 21 & $(26.3)$ & 34 & $(34.0)$ & 17 & $(23.0)$ & \\
\hline & 2 & 18 & $(22.5)$ & 25 & $(23.8)$ & 15 & $(20.3)$ & \\
\hline & 3 & 5 & (6.3) & 4 & (3.8) & 7 & (9.5) & \\
\hline & 4 & 1 & (1.3) & 1 & $(1.0)$ & 1 & (1.4) & \\
\hline
\end{tabular}




\section{Continued}

\begin{tabular}{|c|c|c|c|c|c|c|c|c|}
\hline Thirst & 0 & 68 & $(86.1)$ & 83 & $(79.0)$ & 63 & $(84.0)$ & 0.146 \\
\hline \multirow[t]{4}{*}{$(\mathrm{n}=259)$} & 1 & 6 & (7.6) & 17 & $(16.2)$ & 6 & (8.0) & \\
\hline & 2 & 3 & (3.8) & 4 & (3.8) & 6 & (8.0) & \\
\hline & 3 & 2 & $(2.5)$ & 0 & $(0.0)$ & 0 & $(0.0)$ & \\
\hline & 4 & 0 & $(0.0)$ & 1 & $(1.0)$ & 0 & $(0.0)$ & \\
\hline Getting & 0 & 21 & $(26.3)$ & 21 & $(20.0)$ & 13 & $(17.8)$ & 0.074 \\
\hline tired easily & 1 & 8 & $(10.0)$ & 27 & $(25.7)$ & 17 & $(23.3)$ & \\
\hline \multirow[t]{3}{*}{$(\mathrm{n}=258)$} & 2 & 31 & $(38.8)$ & 44 & $(41.9)$ & 31 & $(42.5)$ & \\
\hline & 3 & 15 & (18.8) & 8 & (7.6) & 6 & $(8.2)$ & \\
\hline & 4 & 5 & $(6.3)$ & 5 & $(4.8)$ & 6 & $(8.2)$ & \\
\hline Sleepiness & 0 & 17 & $(21.3)$ & 17 & $(16.2)$ & 11 & $(14.9)$ & 0.296 \\
\hline \multirow[t]{4}{*}{$(\mathrm{n}=259)$} & 1 & 8 & $(10.0)$ & 29 & $(27.6)$ & 14 & $(18.9)$ & \\
\hline & 2 & 36 & $(45.0)$ & 39 & $(37.1)$ & 32 & $(43.2)$ & \\
\hline & 3 & 7 & (8.8) & 7 & $(6.7)$ & 6 & $(8.1)$ & \\
\hline & 4 & 12 & $(15.0)$ & 13 & $(12.4)$ & 11 & $(14.9)$ & \\
\hline \multirow{5}{*}{$\begin{array}{l}\text { Rough skin } \\
\qquad(\mathrm{n}=260)\end{array}$} & 0 & 28 & $(35.0)$ & 30 & $(28.6)$ & 24 & $(32.0)$ & 0.515 \\
\hline & 1 & 20 & $(25.0)$ & 30 & $(28.6)$ & 13 & $(17.3)$ & \\
\hline & 2 & 23 & $(28.8)$ & 36 & $(34.3)$ & 28 & $(37.3)$ & \\
\hline & 3 & 5 & $(6.3)$ & 8 & $(7.6)$ & 6 & $(8.0)$ & \\
\hline & 4 & 4 & (5.0) & 1 & $(1.0)$ & 4 & (5.3) & \\
\hline
\end{tabular}

Number (\%). Degree: 0 (no symptom), 1 (unrecognizable), 2 (bearable), 3 (unrecognizable if taking medication), and 4 (affecting daily life).

Table 4. Associations of handgrip strength levels with degrees of psychological symptoms in menstruation-related symptoms.

\begin{tabular}{|c|c|c|c|c|c|c|c|c|}
\hline \multirow[b]{3}{*}{ Increase in appetite } & \multirow{3}{*}{$\begin{array}{c}\text { degree } \\
0\end{array}$} & \multicolumn{6}{|c|}{ Handgrip strength } & \multirow{3}{*}{$\begin{array}{c}P \text {-value } \\
0.512\end{array}$} \\
\hline & & \multicolumn{2}{|c|}{ Low $(80)$} & \multicolumn{2}{|c|}{ Middle (105) } & \multicolumn{2}{|c|}{ High (75) } & \\
\hline & & 27 & $(33.8)$ & 30 & $(28.6)$ & 18 & $(24.0)$ & \\
\hline \multirow[t]{4}{*}{$(\mathrm{n}=260)$} & 1 & 22 & $(27.5)$ & 30 & $(28.6)$ & 19 & $(25.3)$ & \\
\hline & 2 & 18 & $(22.5)$ & 34 & $(32.4)$ & 26 & $(34.7)$ & \\
\hline & 3 & 6 & (7.5) & 3 & (2.9) & 7 & (9.3) & \\
\hline & 4 & 7 & $(8.8)$ & 8 & (7.6) & 5 & $(6.7)$ & \\
\hline Irritation & 0 & 19 & $(23.8)$ & 20 & $(19.0)$ & 15 & $(20.0)$ & 0.914 \\
\hline \multirow[t]{4}{*}{$(\mathrm{n}=260)$} & 1 & 17 & $(21.3)$ & 25 & $(23.8)$ & 19 & $(25.3)$ & \\
\hline & 2 & 29 & $(36.3)$ & 47 & $(44.8)$ & 29 & $(38.7)$ & \\
\hline & 3 & 6 & (7.5) & 6 & (5.7) & 4 & (5.3) & \\
\hline & 4 & 9 & $(11.3)$ & 7 & $(6.7)$ & 8 & $(10.7)$ & \\
\hline Depression & 0 & 24 & $(30.0)$ & 30 & $(28.6)$ & 24 & $(32.0)$ & 0.011 \\
\hline$(\mathrm{n}=260)$ & 1 & 10 & (12.5) & 34 & (32.4) & 12 & $(16.0)$ & \\
\hline
\end{tabular}




\section{Continued}

\begin{tabular}{ccccccccc}
\hline & 2 & 28 & $(35.0)$ & 29 & $(27.6)$ & 32 & $(42.7)$ & \\
& 3 & 9 & $(11.3)$ & 7 & $(6.7)$ & 2 & $(2.7)$ & \\
Loss of motivation & 0 & 21 & $(26.3)$ & 28 & $(26.7)$ & 21 & $(28.0)$ & 0.236 \\
$(\mathrm{n}=260)$ & 1 & 18 & $(22.5)$ & 33 & $(31.4)$ & 19 & $(25.3)$ & \\
& 2 & 28 & $(35.0)$ & 34 & $(32.4)$ & 30 & $(40.0)$ & \\
& 2 & 6 & $(7.5)$ & 7 & $(6.7)$ & 0 & $(0.0)$ & \\
Anxiety & 3 & 7 & $(8.8)$ & 3 & $(2.9)$ & 5 & $(6.7)$ & \\
$(\mathrm{n}=260)$ & 4 & 39 & $(48.8)$ & 49 & $(46.7)$ & 45 & $(60.0)$ & 0.037 \\
& 1 & 15 & $(18.8)$ & 33 & $(31.4)$ & 10 & $(13.3)$ & \\
& 2 & 17 & $(21.3)$ & 18 & $(17.1)$ & 14 & $(18.7)$ & \\
& 3 & 4 & $(5.0)$ & 3 & $(2.9)$ & 0 & $(0.0)$ & \\
& 4 & 5 & $(6.3)$ & 2 & $(1.9)$ & 6 & $(8.0)$ &
\end{tabular}

Number (\%). Degree: 0 (no symptom), 1 (unrecognizable), 2 (bearable), 3 (unrecognizable if taking medication), and 4 (affecting daily life).

\section{Discussion}

In the present study, we showed that mean handgrip strength level was $26.0 \pm$ $3.9 \mathrm{~kg}$ in Japanese female university students (mean age: 20.0 years), and this level was similar to the level reported for 19-year-old students in Japan (handgrip strength level: $26.1 \pm 4.7 \mathrm{~kg}$ ) but lower than the level reported for 20 24 -year-old working women $(28.1 \pm 4.6 \mathrm{~kg})$ [5]. These results are consistent with studies conducted in other countries showing that handgrip strength of students is weaker than that of industrial workers [15].

We found that there were associations of handgrip strength levels with degrees of depressive and anxiety symptoms included in menstruation-related symptoms and there tended to be associations between handgrip strength level and physical symptoms such as getting tired easily. Previous studies showed that handgrip strength level was associated with psychological symptoms such as anxiety and depressive symptoms in young to elderly adults [12] [13] [14]. A cohort study conducted in Finland reported that a low level of handgrip strength was associated with depressive symptoms in young males [16]. Since it has been reported that an increase in muscular strength may prevent depression [13], we suggest that an increase in handgrip strength might also prevent psychological symptoms including depression as menstruation-related symptoms. In our survey, other psychological symptoms such as irritation and loss of motivation were not found associated with handgrip strength. Further study is needed to clarify the reason and determine whether handgrip strength directly influences menstruation-related psychological symptoms.

In our study, handgrip strength levels for young students were not found to be associated with degrees of abdominal pain and back pain or with physical discomfort. However, a previous study has reported that women whose ages ranged 
from 20 years to middle age, with low handgrip strength had worse quality of life for pain/discomfort dimensions of European Quality of Life Scale-Five Dimensions, and suggested that handgrip strength reflects pain or discomfort since muscle strength generally decreases when pain is present [12]. The difference in targeted age groups may affect the association of handgrip strength level with pain or discomfort. Moreover, the results might be influenced by recall bias in our study, as the subjects in the previous study were asked only about symptoms present at the time of the study.

We showed that there was no significant difference in handgrip strength according to the phase of the menstrual cycle. This result is consistent with the results of a previous study showing that there was no change in handgrip strength over the menstrual cycle [17]. We also have found that handgrip strength was associated with body height, body weight and BMI. These results are similar to the results of a previous study showing a weak correlation of handgrip strength with BMI and moderate correlations of handgrip strength with body weight and height in young and middle-aged subjects [18]. Similarly, strong correlations of handgrip strength with height and weight and a weak correlation of handgrip strength with BMI were found in subjects aged 22 - 25 years [19]. However, a previous study reported that height and weight of women with a low level of handgrip strength were significantly lower than those of women with a normal level of handgrip strength but that there was no difference in BMI between young and elderly adults [12].

In Japan, handgrip strength has decreased over the past 10 years, especially in the young generation [5]. Schools or health care facilities may let the young female students measure their handgrip strength to assess their physical and psychological health including the menstruation-related symptoms.

This study has several limitations. First, this was a cross-sectional study that has recall bias for the degrees of menstruation-related symptoms. A study targeting women during menstruation is needed. Second, data about medical histories, such as gynecological diseases and psychological diseases, have not been collected. Third, we should have used an objective evaluation scale for symptoms such as Visual Analogue Scale. Finally, our results were obtained from only nursing students at a university in Japan, and generalization from this study is therefore difficult.

\section{Conclusion}

Handgrip strength levels are associated with degrees of depression and anxiety during menstruation as menstruation-related symptoms in female university students in Japan. The results in the present study can be used as fundamental data in further clarifying the relationship between muscle strength and menstruation-related symptoms.

\section{Acknowledgements}

The authors extend their thanks to the participants in this study. 


\section{Conflicts of Interest}

The authors have not declared any conflict of interest.

\section{References}

[1] Health and Global Policy Institute (2018) Survey on Health Promotion and Working Women 2018.

https://hgpi.org/wp-content/uploads/Survey-on-Health-Promotion-and-WorkingWomen-2018_Final-Report_180810_vFinal.pdf

[2] Ikeda, T., Suzuki, Y. and Maeda, T. (2013) Relationships between Menstrual Symptoms, Lifestyle Habit, and Cold Sensitivity in High School Students. Japanese Journal of Maternal Health, 53, 487-496.

[3] Sakama, I. and Kusumi, Y. (2004) The Relationship between Menstrual Symptoms and Life-Styles. Journal of Ibaraki Christian University. II, Social and Natural Sciences, 38, 193-203.

[4] Yamamoto, K., Okazaki, A., Sakamoto, Y. and Funatsu, M. (2009) The Relationship between Premenstrual Symptoms, Menstrual Pain, Irregular Menstrual Cycles, and Psychosocial Stress among Japanese College Students. Journal of Physiological Anthropology, 28, 129-136.

[5] Japan Sports Agency (2019) The Report of FY2018 National Survey on Physical Fitness and Athletic Performance.

https://www.mext.go.jp/sports/b_menu/toukei/chousa04/tairyoku/kekka/k_detail/1 $\underline{421920 . h t m}$

[6] Chen, L.K., Woo, J., Assantachai, P., Auyeung T.W., Chou, M.Y., Iijima, K., Jang, H.C., Kang, L., Kim, M., Kim, S., Kojima, T., Kuzuya, M., Lee, J.S.W., Lee, S.Y., Lee, W.J., Lee, Y., Liang, C.K., Lim, J.Y., Lim, W.S., Peng, L.N., Sugimoto, K., Tanaka, T., Won, C.W., Yamada, M., Zhang, T., Akishita, M. and Arai, H. (2020) Asian Working Group for Sarcopenia: 2019 Consensus Update on Sarcopenia Diagnosis and Treatment. Journal of the American Medical Directors Association, 21, 300-307. https://doi.org/10.1016/j.jamda.2019.12.012

[7] Beaudart, C., Zaaria, M., Pasleau, F., Reginster, J.Y. and Bruyere, O. (2017) Health Outcomes of Sarcopenia: A Systematic Review and Meta-Analysis. PLOS ONE, 12, e0169548. https://doi.org/10.1371/journal.pone.0169548

[8] Wu, Y., Wang, W., Liu, T. and Zhang, D. (2017) Association of Grip Strength with Risk of All-Cause Mortality, Cardiovascular Diseases, and Cancer in Community-Dwelling Populations: A Meta-Analysis of Prospective Cohort Studies. Journal of the American Medical Directors Association, 18, 551. e17-551. e35. https://doi.org/10.1016/j.jamda.2017.03.011

[9] Celis-Morales, C.A., Welsh, P., Lyall, D.M., Steell, L., Petermann, F., Anderson, J., Iliodromiti, S., Sillars, A., Graham, N., Mackay, D.F., Pell, J.P., Gill, J.M.R., Sattar, N. and Gray, S.R. (2018) Associations of Grip Strength with Cardiovascular, Respiratory, and Cancer Outcomes and All Cause Mortality: Prospective Cohort Study of Half a Million UK Biobank Participants. BMJ, 361, k1651.

[10] Peterson, M.D., Duchowny, K., Meng, Q., Wang, Y., Chen, X. and Zhao, Y. (2017) Low Normalized Grip Strength Is a Biomarker for Cardiometabolic Disease and Physical Disabilities among U.S. and Chinese Adults. The Journals of Gerontology: Series $A$, 72, 1525-1531. https://doi.org/10.1093/gerona/glx031

[11] Ortega, F.B., Silventoinen, K., Tynelius, P. and Rasmussen, F. (2012) Muscular Strength in Male Adolescents and Premature Death: Cohort Study of One Million 
Participants. BMJ, 345, e7279. https://doi.org/10.1136/bmj.e7279

[12] Kang, S.Y., Lim, J. and Park, H.S. (2018) Relationship between Low Handgrip Strength and Quality of Life in Korean Men and Women. Quality of Life Research, 27, 2571-2580. https://doi.org/10.1007/s11136-018-1920-6

[13] Lee, M.R., Jung, S.M., Bang, H., Kim, H.S. and Kim, Y.B. (2018) The Association between Muscular Strength and Depression in Korean Adults: A Cross-Sectional Analysis of the Sixth Korea National Health and Nutrition Examination Survey (KNHANES VI) 2014. BMC Public Health, 18, 1123. https://doi.org/10.1186/s12889-018-6030-4

[14] Fukumori, N., Yamamoto, Y., Takegami, M., Yamazaki, S., Onishi, Y., Sekiguchi, M., Otani, K., Konno, S., Kikuchi, S. and Fukuhara, S. (2015) Association between Hand-Grip Strength and Depressive Symptoms: Locomotive Syndrome and Health Outcomes in Aizu Cohort Study (LOHAS). Age and Ageing, 44, 592-598. https://doi.org/10.1093/ageing/afv013

[15] Xiao, G., Lei, L., Dempsey, P.G., Lu, B. and Liang, Y. (2005) Isometric Muscle Strength and Anthropometric Characteristics of a Chinese Sample. International Journal of Industrial Ergonomics, 35, 674-679. https://doi.org/10.1016/j.ergon.2005.02.003

[16] Suija, K., Timonen, N., Suviola, M., Jokelainen, J., Järvelin, M.R. and Tammelin, T. (2013) The Association between Physical Fitness and Depressive Symptoms among Young Adults: Results of the Northern Finland 1966 Birth Cohort Study. BMC Public Health, 13, Article No. 535. https://doi.org/10.1186/1471-2458-13-535

[17] Janse de Jonge, X.A.K., Boot, C.R.L, Thom, J.M., Ruell, P.A. and Thompson, M.W. (2001) The Influence of Menstrual Cycle Phase on Skeletal Muscle Contractile Characteristics in Humans. The Journal of physiology, 530, 161-166. https://doi.org/10.1111/j.1469-7793.2001.0161m.x

[18] Lopes, J., Grams, S.T., Da Silva, E.F., De Medeiros, L.A., De Brito, C.M.M. and Yamaguti, W.P. (2018) Reference Equations for Handgrip Strength: Normative Values in Young Adult and Middle-Aged Subjects. Clinical Nutrition, 37, 914-918. https://doi.org/10.1016/j.clnu.2017.03.018

[19] Chandrasekaran, B., Ghosh, A., Prasad, C., Krishnan, K. and Chandrasharma, B. (2010) Age and Anthropometric Traits Predict Handgrip Strength in Healthy Normal. Journal of Hand and Microsurgery, 2, 58-61.

https://doi.org/10.1007/s12593-010-0015-6 